\title{
A Comparative Study of Transference of Humor in Translations of "The Adventures of Huckleberry Finn" by Mark Twain
}

\author{
Rezvan Barzegar Hossieni \\ Translation Studies, Birjand University and Payame Noor University, Kerman Branch, Iran \\ E-mail:Rezvanbarzegarh@yahoo.com \\ Mohsen Mobaraki (Corresponding author) \\ English Department, University of Birjand, Iran \\ Email: mmobaraki@birjand.ac.ir \\ Maryam Rabani Nia \\ Chabahar Maritime University, Iran \\ E-mail:Amin.Rabani.Maryam@yahoo.com
}

Received: 26-03-2017

Published: 01-11-2017
Accepted: 23-05-2017

doi:10.7575/aiac.ijalel.v.6n.6p.1
Advance Access Published: September 2017

URL: http://dx.doi.org/10.7575/aiac.ijalel.v.6n.6p.1

\begin{abstract}
Translation is a difficult and complex task. Some elements such as linguistic and socio-cultural differences in two languages make it difficult to choose an appropriate equivalent; the equivalent which has the same effect in the target language. In the present study, one of the richest sources of the humor and satire is investigated. Humor is completely obvious in "The Adventures of Huckleberry Finn" by Mark Twain. He tried to laugh at social and cultural problems of his time by this novel. Two translations of this book by Hushang Pirnazar and Najaf Daryabandari are investigated. The author tries to investigate on transference of humor from the source language to the target language by a syntactic strategy of Chesterman. By investigating the text, it will be found out that which translator is more successful in recreation of humor by using the strategies.
\end{abstract}

Keywords: The Adventures of Huckleberry Finn, humor, translation of humor, Hushang Pirnazar

\section{Introduction}

Humor, in most of European languages, means criticism which is provided by a humoristic language. Humor can be in prose or poetry. It challenges the human's mistakes or undesirable behavior, socio-political corruptions and philosophical thoughts. Humor has a significant statue in literature. The humor goes back to the entrance of theatre to Greece and Rome. Nowadays humor as a kind of art has an important statue in literature. Chekhov, Anatole France, George Bernard Shaw, Günter Grass and Edward Albee are the famous scholars in this field. Also in Iran, the tendency to humor goes back to years ago in Persian prose and poetry.

\subsection{Significance of the research}

Today, humor is a very powerful artistic form used to criticize specific human behaviors. In addition to content, form is also important in a humoristic work. Humor is a device which is used by poets and creative writers. Humoristic elements can be found in literary works in almost all languages. So for a translator especially a literary translator, the knowledge of translating humor is very important. The translator needs some guidance or theories in order to reflect the humoristic effects into the TT. In this case, the translators will be acquired with some strategies which make the humor of the ST more clear for the readers of the TT and reproduce an acceptable translated piece of literature. This research is done in order to find out the humoristic devices used in a great satirical novel, "The Adventures of Huckleberry Finn", and to investigate on different strategies which are used in translating humoristic devices.

Research question: Were translators able to recreate the same humoristic features of the source text in the target text by using the presented strategies? Which translator was more successful in transference of humor?

Research hypothesis: Both translators could recreate the humoristic feature by using the presented strategies.

\subsection{Types of humor}

Humoristic works have an important role in historical studies of a culture and society. Therefore, humor is a sociocultural phenomenon in addition to its linguistic aspects. Humor is something's "quality of being funny" (Vandaele, 
2002: 153). linda Broeder (2007: 35) quotes Van der Parre (1985: 393) that, humor functions as a connector and tries to capture and retain the attention of the audience. As mentioned above, humor can be divided into two categories: linguistic and cultural. The first one is a kind of the humor which is related to the linguistic aspects of the humor, for example using wordplays such as pun and malapropism in the text. "Humour based on wordplay may have 'silly' or 'witty' undertones, slapstick may strike people as 'simplistic', nonsense talk in an unfamiliar environment may be slightly frightening etc." (Vandaele, 2002: 154).

According to the above definitions, it is obvious that among these literary devices there are so many overlapping devices which lead to more confusion to understand the intention of the author.

In this research, two linguistic games in humor are investigated: repetition and parallelism.

According to "The Dictionary of Literary and Rhetorical Terms", (2007: 26) repetition is a device in which words, sounds, and ideas are used more than once to enhance rhythm and to create emphasis. Bergson states that repetition refers to a regular occurrence of a scene, producing a humorous effect because of the expectation it builds (1911: 90).

According to "The Dictionary of Literary and Rhetorical Terms", (2007: 26) parallelism refers to a grammatical or structural similarity between sentences or parts of a sentence. It involves an arrangement of words, phrases, sentences, and paragraphs so that elements of equal importance are equally developed and similarly phrased often referred to as parallelism.

\subsection{Translation of humor}

Huang (2011: 14) states that in literary translation, the typical features of the source literary text not only need to be taken into account, but also the influential elements from the target perspective, such as the linguistic and cultural differences and the target readers must be considered. Literary texts are characterized by rhetorical and aesthetic values, which are expected to be captured and maintained in a literary translation. One of the main tasks for literary translator is to reproduce the rhetorical and aesthetic values of the original text. In literary translation, the form links to the content; but in non-literary translation the content may be considered detachable from the form or structure. In prose, like poetry, a certain linguistic features can also have a certain textual function. For example, the repetition in Hemingway's "In Another Country" is a linguistic feature to express the character's tedious life.

Rener (1989: 161) states that a 'rhetorical' sentence is "a carefully and skillfully assembled construction".

Nida (1964), cited in Venuti's book (2000: 154) that content and form affect each other. He believes that "the content of a message can never be completely abstracted from the form and form is nothing apart from content". The linguistic differences, however, pose a great challenge in literary translation. In prose, the linguistic differences should also be carefully considered. For instance, the pun is an extremely language-dependent wordplay.

Translation is a complex and difficult task. Translator must pay enough attention to translation of this kind of works. The translator must be sure that the reader can recognize humor in the text. In addition, he/she have to make sure that the function of humor in the target text is the same as its function in the source text. The first problem in translation of humor is its identification. Humor is usually provided indirectly and it makes the translator unable to recognize it. The lack of socio-cultural equivalence between source and target languages is another problem in translation of humor.

Liu Lei (2010: 7) states that "humor is shared by people from every nation. However, different nations have different kinds of sense of humor, closely related to religion, ideology, society, politics and culture. Therefore, although humor has been studied for a very long time, most are from the perspective of literature, art, sociology, psychology pragmatics or linguistics. Some scholars doubt that humor can be fully translated into another language because humor is languagespecific and culture-specific. Only a few scholars study the translation of humor."

Attardo (1994: 95) believes that "there are two kinds of jokes (...) on one side, we have referential jokes, and on the other, we have verbal jokes. The former are based exclusively on the meaning of the text and do not make any reference to the phonological realization of the lexical items (or of other units in the text), while the latter, in addition to being based on the meaning of the elements of the text, make reference to the phonological realization of the text."

Referential jokes refer to humor focused on the pragmatic level. They are humor which play with language. However, verbal jokes refer to humor focused on the linguistic level and are playing through language

Regarding to humor at the linguistic level John Richard Morton Gledhill (2001: 170) declares that the translation of humor and paranomasia is yet another important neglected field in literary translation theory. Delabastita (1996: 127) rightly sees this area as not only difficult but he also opens up the problem of defining the limits of translation.

\subsection{Mark Twain's humor}

The case study of the current research as mentioned before is "The Adventures of Huckleberry Finn" and its two Persian translations. The reason behind choosing this work as the case study is that Twain is a famous satirist and this novel is a rich resource of satire and humor.

According to Olivier Nyirubugara (2001: 5), Twain started as a humorist in his brother Orion's magazine, The Journal. He used to quarrel at the articles to publish with Orion who had no sense of humor. He thought that they need a little humor, things that make people laugh, something which give a little life to the journal. Twain already had the sense of humor which he would develop first as a journalist, then as a lecturer and finally as a novelist and essayist. Mark Twain was convinced that telling a story without humor is like offering a meal without salt. That story would not be tasty. Thus, humor made him a humorous fictionist. Twain wrote about his personal experiences and the things he knew from 
first-hand experience. The various characters in "The Adventures of Huckleberry Finn" are based on the types Twain had encountered both in his hometown and while working on the river boat on the Mississippi river. Many of vices exist in "The Adventures of Huckleberry Finn" had been witnessed by the author, who was sometimes victim of them. Twain's life and experience provided him with much material, which is estimated at four or five of all his writings. This proves that Mark Twain dealt with a situation that really existed and which he knew very well.

He was lauded as the greatest American humorist of his age. Jelliffe (1956: 88) quoted William Faulkner (1955) that Twain is called "the father of American literature."

\section{Theoretical framework}

Chesterman (1993: 1) says that "to translate without a theory would therefore be to translate blind. To translate without seeing or knowing what one is doing. With no self-awareness, no self-criticism. It would mean relying entirely on common sense, one might say."

He (2000: 1) says that strategy memes are the most useful sets of professional translation memes. He (ibid: 4) states that these memes are essential conceptual tools of the translator's trade and defines strategy as "any well-established way of solving a translation problem." Using this strategies makes a diference between a professional and an amateur translator. So in Chesterman's viewpoint (ibid: 7) "a memetically enlightened professional, then, is someone who can recognize a typical problem, register the relevant contextual conditions, and select an appropriate strategy."

Chesterman (1997: 92) distinguishes between comprehension strategies and production strategies. Comprehension strategies deal with understanding and analyzing the source text and the whole nature of translation commission. Production strategies are the result of various comprehension strategies. These strategies have to do with how the translator manipulates the linguistic material in order to produce an appropriate TT.

Chesterman has divided production strategies to 3 categories: semantic, syntactic and pragmatic strategies. Each strategy has 10 techniques. The author's focus in this research is on one of techniques of syntactic strategy.

\section{Syntactic strategies}

Chesterman (1997: 94) declares that these strategies "may be thought of as involving purely syntactic changes of one kind or another. Larger changes may obviously tend to involve smaller ones too. Syntactic strategies primarily manipulate form". The strategies are as bellow:

1. Literal translation 2. Loan, calque 3. Transposition 4. Unit shift 5. Phrase structure change 6. Clause structure change 7. Sentence structure change 8 . Cohesion change 9. Level shift 10. Scheme change.

The $10^{\text {th }}$ technique, scheme change, is used in this research. He (ibid: 99) declares that "this refers to the kinds of changes that translators incorporate in the translation of rhetorical schemes such as parallelism, repetition, alliteration, metrical rhythm etc."

He (ibid: 100) believes that the translator can choose between three basic alternatives:

1. ST scheme $X \rightarrow$ TT scheme $X$. That is, if the ST scheme is judged to be relevant to the translation task, it can be (to some extent) preserved: in fact no change.

2. ST scheme $X \rightarrow$ TT scheme Y. That is, the ST scheme can be changed to another scheme that is deemed to serve an appropriate or similar function in the TL.

3. ST scheme $X \rightarrow$ TT scheme $ø$. That is, the scheme is dropped altogether.

4. ST scheme $\varnothing \rightarrow$ TT scheme X. Here, the translator opts to use a rhetorical scheme of some kind, although not prompted directly to do so by the ST.

\section{Review of literature}

Researching on humor is a wide field and many scholars have worked on it. The aim of this research is translation of humor. Salvatore's general theory of verbal humor in 1994 focused on linguistic methods of humor translation. He provided 6 parameters for providing humor. Using these 6 parameters helps translators to recreate the humor in target language. Also in 2007, Vandaele, the researcher and professor of university of Oslo, investigated on translation of humor. In his opinion, translation of humor is different from other fields; therefore, translators cannot translate the humoristic texts as other texts (Vandaele, 2007: 1-6). In addition, Delabastita studied on translation of wordplays which are types of linguistic humor. He declares that the wordplays make some problems in translatability of a work because each language is different in form and meaning (2004: 601). Linda Broeder (2007) also, in her article, "Translating Humour: The Problems of Translating Terry Pratchett", presented some solutions in translating humor. Her work is divided into two parts. In the first part, she talked about the translation of parody to Dutch in the works of Terry Pratchett. In the second part, she focuses on translating satire, then translating pun and after that language varieties. In each of these sections, she gave a model to translate these techniques. She also provides some translation procedures to translate them. Brigid Maher (2011) in her book "Recreation and Style: Translating Humorous Literature in Italian and English" explores the translation of literary and humorous style, including comedy, irony, satire, parody and the grotesque, from Italian to English and vice versa. By analyzing translations of works by Rosa Cappiello, Dario Fo, Will Self and Anthony Burgess, the author explores literary translation as a form of exchange between translated and receiving cultures. At the end, she recounts her own strategies in translating the work of Milena Agus. 


\section{Methodology}

\subsection{Corpus}

As mentioned above, to investigate the extent that the translators had been successful in transferring humor by using strategies, a book titled "The Adventures of Huckleberry Finn" written by famous American writer Mark Twain (1884) was chosen by the researcher.

The target texts that are used by the researcher are two translated versions of "The Adventures of Huckleberry Finn". Najaf Daryabandari translated the first target text (TT1). He is an Iranian translator of works from English into Persian. In addition to being a translator, he has also a hand in literature, philosophy, and humor. At the beginning of his translation of the novel, he talked about different aspects of the novel such as humoristic aspect which is the subject of this thesis.

Hushang Pirnazar translated the second target text (TT 2). He is an author and translator. He translated "the Adventures of Huckleberry Finn" in 1957. In the preface of his translation of "the Adventures of Huckleberry", Hushang Pirnazar (1961) declares that it is a story of a homeless boy and a runaway slave and people whose lives are ludicrous because of great sadness.

\subsection{Data collection}

The researcher analyzed different models, approaches as well as quotes and suggestions by the scholars in the field of parallelism, repetition and wordplay translation in order to come up with a model for the translation of humor. The unit of investigation in this study was text. The first step in data collection was to recognize and find parallelism and repetition in English text and its translations. Therefore, 496 pages (all pages) of the novel and their translations were studied in order to find 30 examples of repetition and 20 examples of parallelism.

\subsection{Procedure}

Firstly, the researcher tried to recognize the parallelism and repetition in the source text and found their equivalents in the target texts. Then each translation version is compared and contrasted based on scheme change strategy to see if it has been applied. After specifying the strategy applied by each translator, four tables are drawn as follow.

\section{Data analysis}

Some examples of parallelism and repetition are provided and discussed in the following:

\section{NOTICE}

PERSONS attempting to find a motive in this narrative will be prosecuted; persons attempting to find a moral in it will be banished; persons attempting to find a plot in it will be shot."(p. 1)

$$
\begin{aligned}
& \text { هT 1) }
\end{aligned}
$$

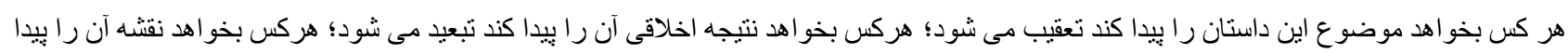

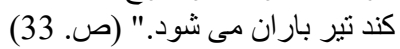

$$
\begin{aligned}
& \text { (TT 2): حذف بان }
\end{aligned}
$$

This sentence has a special scheme as Parallelism. As we said before, it is the repetition of the same pattern of words or phrases within a sentence or passage to show that two or more ideas have the same level of importance. Twain used it in his novel as a humoristic device. The structure of three sentences above is repeated and Daryabandari perfectly, maintained the repetition based on the grammatical structure of the Persian language. Based on Chesterman's syntactic strategies, the first translator used the scheme change strategies to translate these sentences. Daryabandari used the first procedure which is ST scheme $\mathrm{X} \rightarrow \mathrm{TT}$ scheme $\mathrm{X}$. It means that the parallelism is preserved. But Pirnazar has completely omitted the sentences and missed the humor of the text.

2. I stood a-looking at him; he set there a-looking at me, with his chair tilted back a little. (p. 18)

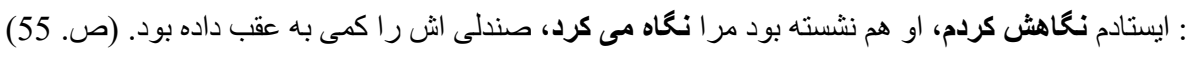

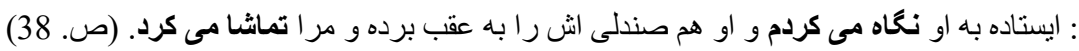

Parallelism exists in two sentences of the ST because the structure of two sentences is the same. Daryabandari has used the first strategy of scheme change which is ST scheme $\mathrm{X} \rightarrow$ TT scheme X. It means parallelism can be (to some extent) preserved. However, Pirnazar has used the third strategy of scheme change which is ST scheme $\mathrm{X} \rightarrow \mathrm{TT}$ scheme $\emptyset$. It means, the scheme (parallelism) is dropped. Also repetition is a device which Twain used to add humor to the text. The verb "a-looking" is repeated two times. Daryabandari translated both of them as "نحكاه كردن", but Pirnazar has translated them once as "نماشا كردن" and the next one as "نحاه كردن". Therefore, Daryabandari has used the first strategy and Pirnazar has used the third one. 
3. Every time he got money he got drunk; and every time he got drunk, he raised Cain around town; and every time he raised Cain he got jailed. (p. 21)

$$
\begin{aligned}
& \text { (TT 1): هر بار كه يول به دستش مى رسيد مى رفت مست مى كرد، هر بار هم كه مست مى كرد تو شهر عربده مى كثيد، هر بار هم كه عربده مى }
\end{aligned}
$$

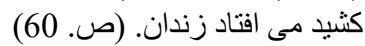

$$
\begin{aligned}
& \text { (TT 2): هر وقت يول مى كرفت مست مى كرد و هر دفعه ممت مى كرد شهر را شلوغ مى كرد و هر دفعه شلوغ مى كرد به حبس مى افتاد. (ص. 43) }
\end{aligned}
$$

Both translators have used the first strategy of scheme change in translating parallelism. They preserved the scheme of the ST sentences in TT sentences. So the humoristic feature of the ST is transferred to the TT. Also the word "every time" is repeated 3 times in the ST. Daryabandari has translated it as" هر بار". He used the first strategy of scheme

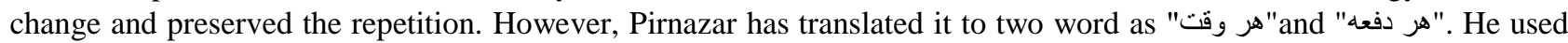
"هر "هر وقت" two times, ance. It can be said that Pirnazar also preserved the scheme but to some extent. It is the first strategy of scheme change. Therefore, both translators have preserved the scheme and could transfer the humoristic feature.

4. Every time a man died, or a woman died, or a child died ... (p. 88)

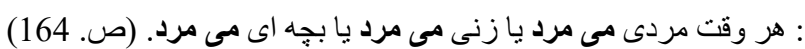

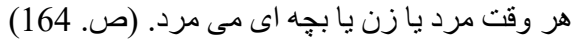

In this sentence the parallelism which is Twain's humoristic device is preserved in the first sentence. So translator has used the first strategy of scheme change. But Pirnazar has omitted "died" and mentioned it just once. So he used the third strategy of scheme change and could not transfer the humoristic feature.

5. They all smoked and talked, and I eat and talked." (p. 84)

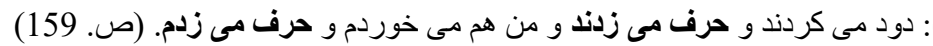

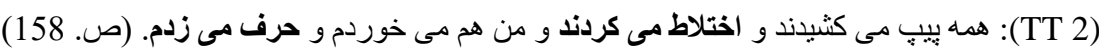

The parallelism in both translations has preserved. The structure of both translations is similar to the sentence of the ST. so translators have used the first strategy of scheme change in transferring the parallelism. The word "talked" is repeated two times in the ST. Daryabandari has translated it as "حرف زدن" and again used the first strategy and preserved the scheme of the ST, but Pirnazar has translated it to "حرف زدن" and "ختلاط كردن" and "حرن" Therefore, he used the third strategy of scheme change and dropped the scheme and could not transfer the humoristic feature.

6. It was a mighty nice family, and a mighty nice house, too. (p. 85)

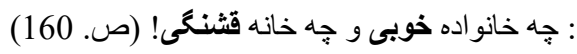

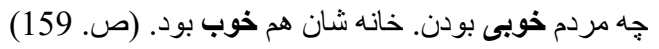

Daryabandari, based on the structure of the TT, could transfer the parallelism to the TT. He used the first strategy of scheme change. But Pirnazar is not successful in translating the scheme and dropped it. The third strategy of scheme change is used in the second translation. "Mighty nice" is an example of repetition in this sentence. The first translator

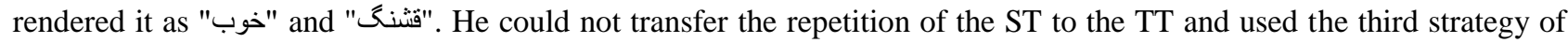
scheme change. But Pirnazar has used "خوب" for it. He used the first strategy and preserved the scheme of the ST in the TT.

7. It was awful thoughts and awful words (p. 180)

$$
\begin{aligned}
& \text { ) : جه فكر بدى و جه حرف بدى. (ص. 289) }
\end{aligned}
$$

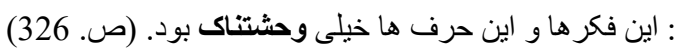

The repetition of "awful" is preserved in the first rendition and dropped in the second one. The first translator used the first strategy and the second one used the third strategy. So Daryabandari has preserved the humoristic feature of the ST in the TT.

8. ...thinking and thinking... (p. 176)

$$
\begin{aligned}
& \text { (T) ... فكر كردند و فكر كردند... (ص. 283) } \\
& \text { (T) ... فكر مى كردند و نقشه مى كثيدند.... (ص. 320) }
\end{aligned}
$$

"Thinking" is repeated in the ST. Daryabandari has preserved the repetition in the TT and used the first strategy of scheme change, but Pirnazar has used "نقتشه كثيدن" and "فكركردن for the single word "thinking". He used the third strategy of scheme change and dropped the repetition. So he could not transfer the humoristic features. 
9869. But now it did; and it stayed with me, and scorched me more and more." (p. 75)

$$
\begin{aligned}
& \text { T): اما حالا كه حاليم شده بود دست از سرم برنمى داشت و دلم را مى خورد و مى خورد. (ص. 147) }
\end{aligned}
$$

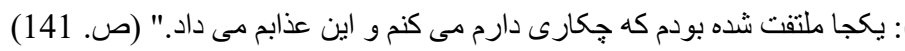

"more and more" is a repetition which Twain uses to add humor. Daryabandari has translated it in the best way by repeating verb "خوردن" two times. He used the first strategy of scheme change and preserved it by repeating a verb. But Pirnazar has missed repetition in his rendition and dropped it. He used the third strategy of scheme change.

Table 1. The frequency of strategies used in translation of repetition

\begin{tabular}{|c|c|c|c|c|}
\hline Scheme change & $\begin{array}{c}\text { ST scheme } X \rightarrow \\
\text { TT scheme } X\end{array}$ & $\begin{array}{c}\text { ST scheme } \mathrm{X} \rightarrow \\
\text { TT scheme Y }\end{array}$ & $\begin{array}{l}\text { ST scheme } X \rightarrow \\
\text { TT scheme } \varnothing\end{array}$ & $\begin{array}{l}\text { ST scheme } \varnothing \rightarrow \\
\text { TT scheme X }\end{array}$ \\
\hline TT1 & 27 & 0 & 3 & 0 \\
\hline TT2 & 4 & 0 & 26 & 0 \\
\hline
\end{tabular}

Table 2. The frequency of strategies used in translation of parallelism

\begin{tabular}{|c|c|c|c|c|}
\hline Scheme change & $\begin{array}{l}\text { ST scheme } X \rightarrow \\
\text { TT scheme } X\end{array}$ & $\begin{array}{c}\text { ST scheme } X \rightarrow \\
\text { TT scheme } Y\end{array}$ & $\begin{array}{r}\text { ST scheme } X \rightarrow \\
\text { TT scheme } \varnothing\end{array}$ & $\begin{array}{l}\text { ST scheme } \varnothing \rightarrow \\
\text { TT scheme X }\end{array}$ \\
\hline TT1 & 20 & 0 & 0 & 0 \\
\hline TT2 & 4 & 0 & 16 & 0 \\
\hline
\end{tabular}

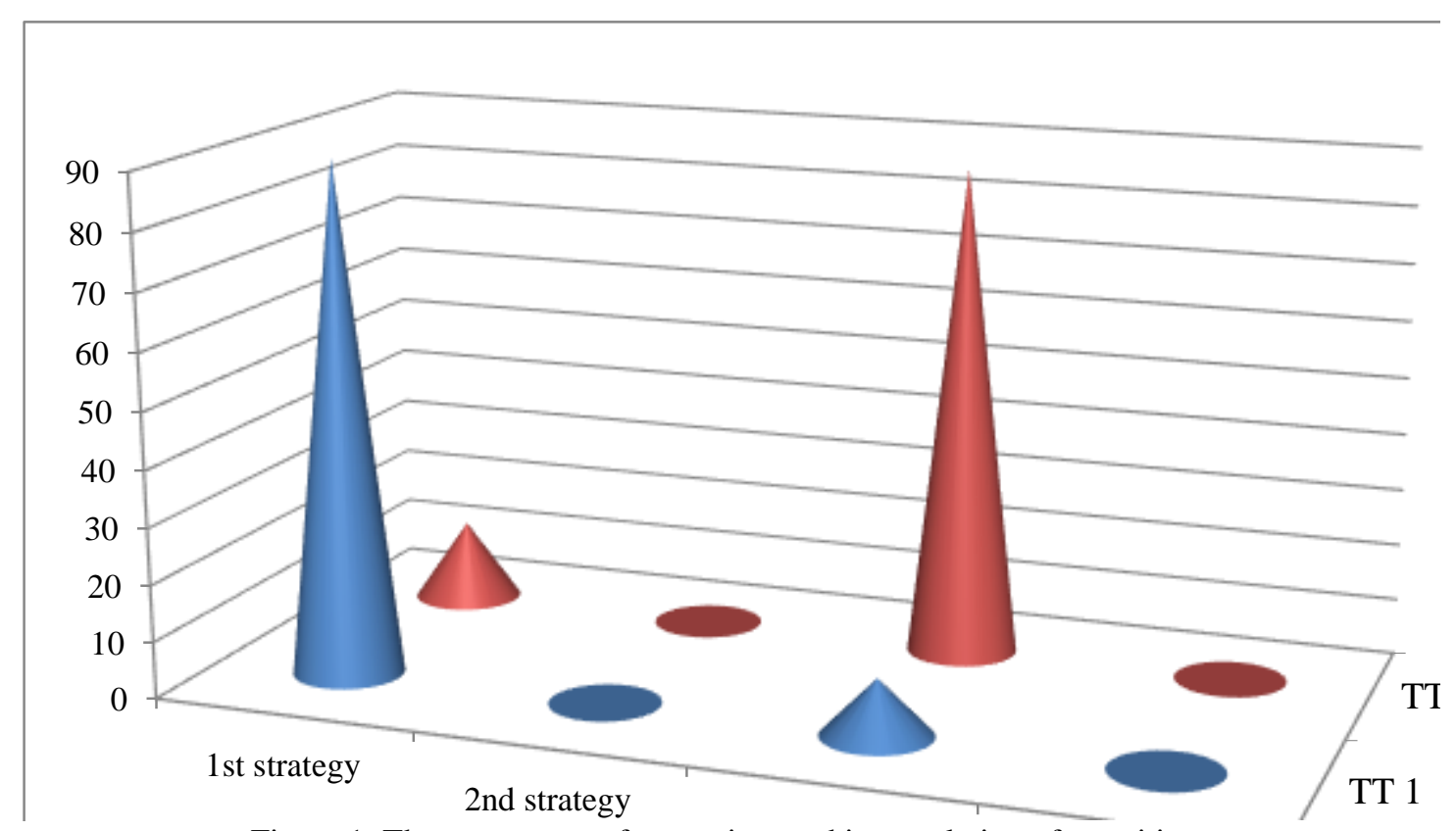

Figure 1. The percentage of strategies used in translation of repetition 


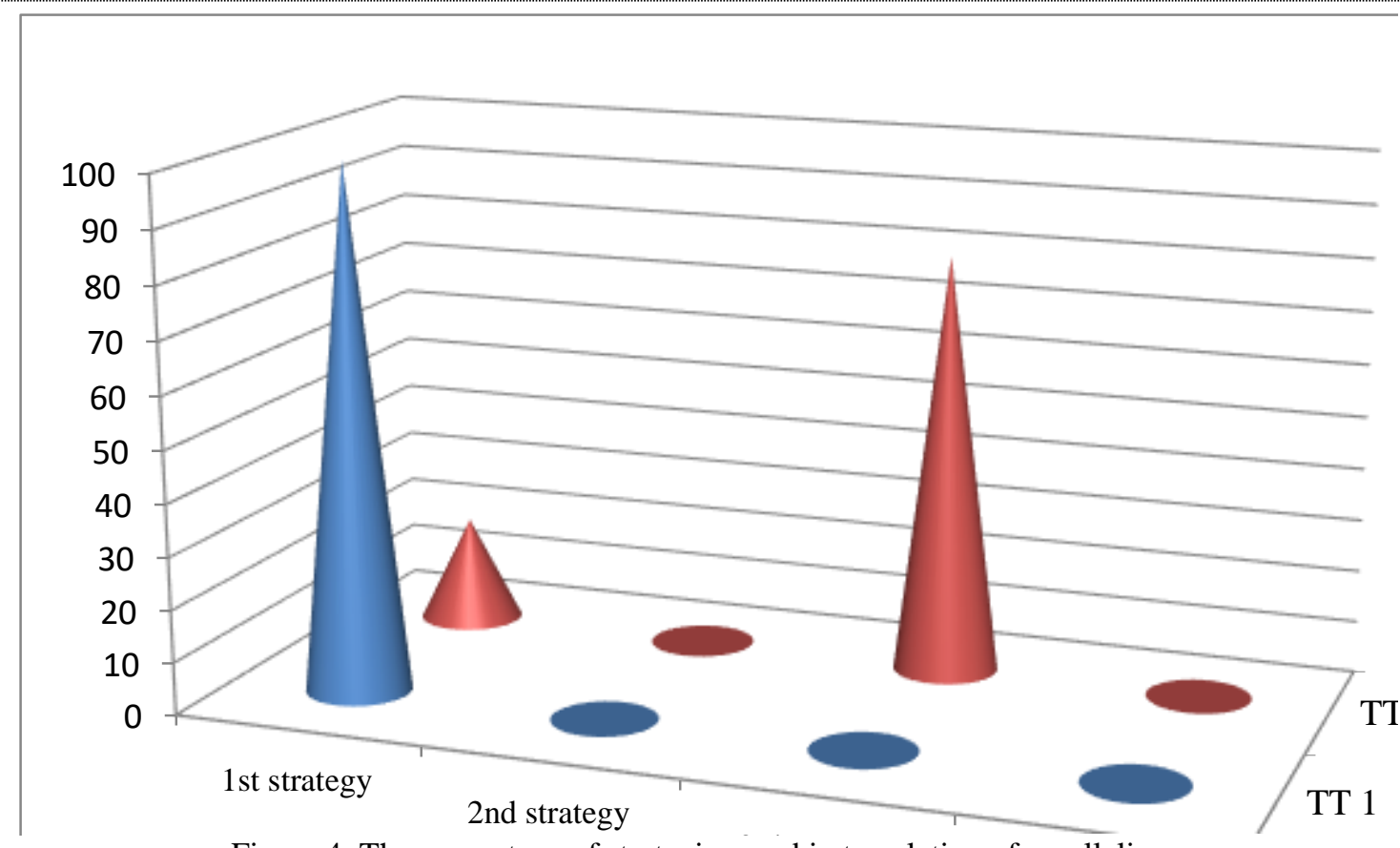

Figure 4. The percentage of strategies used in translation of parallelism

\section{Discussion}

As illustrated above two translators transferred parallelism and repetition in different ways. As it is shown in the table1, 30 instances of repetition were identified and investigated. Daryabandari used the first strategy of scheme change which is ST scheme $\mathrm{X} \rightarrow \mathrm{TT}$ scheme $\mathrm{X}$, in 27 instances and the third strategy which is ST scheme $\mathrm{X} \rightarrow$ TT scheme $\varnothing$, in 3 instances. These results show that he could transfer the humoristic effect of repetition in most cases. It is also shown that Pirnazar has used the first strategy in 4 instances and the third one in 26 instances. It is clear that Daryabandari is more faithful to the linguistic form of the ST and the first strategy is the best one in conveying the repetition which is a humoristic device in this novel. According to table 2, 20 examples of parallelism are investigated. Daryabandari used the first strategy in all 20 instances but Pirnazar used the first strategy in 4 examples and the second one in 16 examples. These results show that Daryabandari created the same effect in the TT in all cases but Pirnazar could not transfer the humoristic effect. Figures 3 and 4 show the percentage of scheme change strategy used in translation of repetition and parallelism in two different translations of the novel.

\section{Conclusion}

As mentioned above translation of humor has a significant statue in literary translation. The linguistic and cultural features of humor make some problems in translation. Because of the unequal structures of source and target language, the translator encounters difficulties in translating linguistic features of humor. Therefore the investigation on transference of humor is a significant field in comparative literature. In order to produce a version which contained the same humorous effects of the original, the translator should be able to utilize creative strategies. According to tables it can be said that two translators rendered completely different and used different strategies. Generally Daryabandari could transfer repetition and parallelism to the target language but Pirnazar was not successful in its transference and could not recreate humor in the target text. The results of this study fostered several points of discussion such as the problems with transferring humor, the amount of creativity a translator can use and different strategies of scheme change, which can be used in translating parallelism and repetition as two humoristic tools. The findings of this study may be useful for translators entering the area of literary translation and humoristic works. The results can also be used in the evaluation of a translated satirical work.

\section{References}

Attardo, S. (1994), Linguistic Theories of Humor,Mouton de Gruyter, Berlin [etc.]

Bergson, H. L. (1911), Laughter: An Essay on the Meaning of the Comic, translated by C. Brereton and F.Rothwell, MacMillan, London.

Broeder, L. (2007). Translating Humour: The Problems of Translating Terry Pratchett. Retrieved August 5th, 2013, from:

http://igitur-archive.library.uu.nl/student-theses/2010-0325 200222/MA_thesis_Linda_Broeder_UU_2007.pdf

Chesterman, A. (1993), Translation as theory. Kaantaja. No. 1.

Chesterman, A. (1997), Memes of Translation: The spread of ideas in Translation Theory, John Benjamins, Amsterdam and New York. 
Chesterman, A. (2000), Memetics and Translation Strategies, Retrieved on September 7th, 2013, from:

http://www.helsinki.fi/ chesterm/2000iMemetics.html

Delabastita, D. (1996), "Introduction”. Wordplay and Translation. Special issue of The Translator. Studies in Intercultural Communication, Delabastita, D. (ed),St Jerome Publishing, Manchester, pp. 127-135.

Delabastita, D. (2004). "Wordplay as a translation problem: a linguistic perspective." Übersetzung, translation, traduction, Harald Kittel, Armin Paul Frank, Norbert Greiner, Theo Hermans, Werner Koller, José Lambert, Fritz Paul (eds.), pp, 600-606. Berlin: Mouton de Gruyter.

Huang, X. (2011),Stylistic Approaches to Literary Translation: With Particular Reference to English-Chinese and Chines-English Translation, The University of Birmingham. Retrieved August 10th, 2013, from:

http://etheses.bham.ac.uk/2949/1/Huang_x_11_PhD.pdf.

Jelliffe, R. A. (1956),Faulkner at Nagano, Kenkyusha Ltd, Tokyo.

Lei, L. (2010),Translation of Humor in Ch'ienChungshu's "Weicheng" in Jeanne Kelly and Nathan K. Mao's Version: From the Perspective of Reception Aesthetics. University of Wisconsin-Platteville. Retrieved September 3th, 2013, from: http://minds.wisconsin.edu/bitstream/handle/1793/43583/Liu,\%20Lei.pdf?sequence=1

Maher, B. (2011). Recreation and Style: Translating Humorous literature in Italian and English. Amsterdam: John Benjamins.

Morton Gledhill, J. R (2001),Strategies in Translation: A Comparison of the Helen Lowe-Porter and David Luke Translations of Thomas Mann's TonioKröger, Tristan and Der Tod in Venedig within the Context of Contemporary Translation Theory. Retrieved August 6th, 2013, from:

http://nbnresolving.de/urn/resolver.pl?urn=nbn\%3Ade\%3Agbv\%3A547-200300472

Nyirubugara, O. (2001),Mark Twain's Satirical Approach to Mind-19th Century American Society as Depicted in The Adventures Of Huckleberry Finn. University of Bangui. Retrieved on September 1th, 2013, from:

www.olny.nl

Office of Curriculum and Instruction Subject. (2007-2008), The Dictionary of literary and rhetorical terms. Retrieved on September 4th, 2013, from:

http://ww2.bentonschools.org/ bentonsc/images/LitTermsDictionary.pdf

Rener, F. M. (1989),Interpretation: Language and Translation from Cicero to Tytler. Atlanta G. A, Amsterdam.

Vandaele, J. (2002)," Introduction - (Re-) Constructing Humor: Meanings and Means",The Translator, 8(2), pp. 149172.

Vandaele, J. (2007), “Humor in Translation”, Translation Review. pp, 1-6, Retrieved on January $12^{\text {th }} 2015$.

Venuti, L. (ed.) (2000),The Translation Studies Reader,Routledge,London.

$$
\begin{aligned}
& \text { مارك، نو اين، 1380، سركنشت هكلبرى فين، ترجمه نجف دريابندرى، انتشار ات خو ارزمى، جاب سوم،تهران. }
\end{aligned}
$$

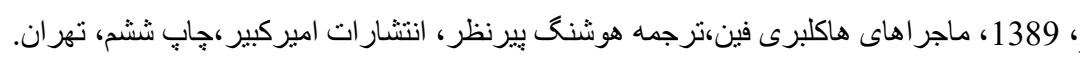

